\title{
A ADOÇÃO DE UM PROGRAMA AMPLO DE PLANEJAMENTO E CONTROLE E SEU IMPACTO NO DESEMPENHO EMPRESARIAL
}

\section{THE ADOPTION OF A WIDE PROGRAM OF PLANNING AND CONTROL AND ITS IMPACT ON CORPORATE PERFORMANCE}

\author{
Lucio Pandolfi Jr. ${ }^{1}$; Wilson Toshiro Nakamura ${ }^{2}$; Diógenes Manoel Leiva Martin ${ }^{3}$; Douglas Dias \\ Bastos $^{4}$ \\ ${ }^{1}$ Universidade Presbiteriana Mackenzie - UPM - São Paulo - Brasil \\ luciopandolfi@yahoo.com.br \\ ${ }^{2}$ Universidade Presbiteriana Mackenzie - UPM - São Paulo - Brasil \\ wtnakamura@uol.com.br \\ ${ }^{3}$ Universidade Presbiteriana Mackenzie - UPM - São Paulo - Brasil \\ diomartin@mackenzie.br \\ ${ }^{4}$ Universidade Presbiteriana Mackenzie - UPM - São Paulo - Brasil \\ dobastos@uol.com.br
}

\begin{abstract}
Resumo
Planejar e controlar são funções inerentes ao processo administrativo, sendo que existem determinados procedimentos básicos que norteiam estas atividades. $O$ conjunto destes procedimentos compõe o modelo tradicional de planejamento e controle. Contudo, é crescente o questionamento no meio acadêmico e empresarial, sobre a efetividade do modelo tradicional de planejamento e controle. Ao mesmo tempo vêm surgindo metodologias alternativas para a execução de tais funções, que sugerem uma análise crítica dos procedimentos tradicionais, questionando a validade dos mesmos quanto à geração de valor. Este estudo, conduzido junto a uma amostra de empresas brasileiras com ações negociadas na Bovespa, objetivou evidenciar uma relação estatística entre a existência de um programa sistemático de planejamento e controle (budgeting), e a obtenção de um resultado financeiro operacional superior. Paralelamente também foi pesquisada a aderência de novas metodologias bem como o grau de satisfação das empresas em relação aos seus procedimentos de planejamento e controle.
\end{abstract}

Palavras-chave: planejamento e controle; orçamento; valor.

\section{Introdução}

Para Porter (1989) a obtenção de vantagem competitiva é fator primordial para qualquer organização, constituindo-se na essência de seu desempenho em mercados competitivos. Para o autor, o sucesso ou o fracasso de qualquer empresa está diretamente relacionado à obtenção de vantagem competitiva. Aaker (2001) obteve como resultado de uma ampla pesquisa efetuada junto a administradores de 248 diferentes negócios nas indústrias de serviço e alta tecnologia, uma 
identificação das fontes de vantagem competitiva sustentável, mais freqüentemente empregada. Dentre elas foram citadas: a existência de objetivos estratégicos, a boa coordenação, a existência de um planejamento de curto prazo e um bom conhecimento do negócio.

Os autores citados acreditam que um programa sistemático de planejamento e controle dos lucros, desde que apropriadamente desenvolvido, implementado e utilizado, contribui de maneira decisiva não só para o progresso do empreendimento, como também é fonte de vantagem competitiva, gerando criação de valor aos acionistas. Esses autores, como muitos outros, são adeptos da Teoria do Planejamento e Controle sugerida por Welsch et al. (1988), que pressupõe que o fator primário de sucesso numa empresa é a competência com que se gerencia o planejamento e o controle das atividades empresariais.

É inquestionável o fato de que a maioria das empresas possui algum tipo de mecanismo que propicia o planejamento e o monitoramento de suas ações operacionais. Esta cultura de planejamento e controle dista de longa data. Já em 1958, Sord e Welsch obtiveram como resultado de uma pesquisa, a constatação de que mais de 96\% das empresas americanas com fins lucrativos utilizavam um programa amplo de planejamento e controle de resultados em bases permanentes (WELSCH, 1983).

Para Banham (2000), muitas empresas investem muito tempo, energia e recursos financeiros desenvolvendo estes planos somente para mudá-los ou até mesmo ignorá-los. Dentre os muitos críticos do processo orçamentário, encontram-se executivos como Jack Welch, que afirmou ser o budget o veneno da América corporativa (HOPE; FRASER, 2003). Também importantes acadêmicos vêm questionando de maneira mais severa o processo orçamentário feito nos moldes tradicionais. Libby e Lindsay (2003) afirmam que as empresas hoje necessitam ser mais flexíveis e responsivas para lidar com as imprevisíveis mudanças, hiper competição, além do fato dos consumidores serem cada vez mais volúveis.

De acordo com Jensen (2001), o orçamento corporativo é uma piada e todos sabem disso. Para ele o processo consome muito tempo dos executivos e encoraja os gerentes a mentirem e a enganarem, podendo inclusive gerar erosão de valor nas organizações. Para Hope e Fraser (2003), os analistas de mercado não estão preocupados ou mesmo interessados em metas fixas de performance ou planos orçamentários, pois eles sabem que as circunstâncias estão sempre mudando. Estão sim, interessados na capacidade das empresas de entregarem suficientes quantidades de fluxos de caixa livre para dar suporte ao crescimento dos dividendos e do preço das ações.

Diante de um contexto onde é crescente a polêmica envolvendo o processo orçamentário, este estudo visou correlacionar o efetivo impacto de um programa sistemático de planejamento e controle dos lucros, nos resultados financeiros de natureza operacional das empresas, no médio e 
longo prazo. Sendo assim a pesquisa foi conduzida no sentido de evidenciar uma associação entre a adoção de um modelo sistemático de planejamento e controle e a obtenção, por parte das empresas, de índices de rentabilidade acima da média no segmento em que atuam.

A justificativa desta pesquisa está relacionada ao crescente interesse, seja no meio acadêmico, seja no meio executivo, quanto a real necessidade de um programa sistemático de planejamento e controle dos lucros. Deve-se ressaltar que o interesse é crescente face, não apenas aos progressivos questionamentos críticos realizados em relação ao processo orçamentário, mas também em virtude do surgimento de metodologias alternativas ao modelo tradicional. Sendo assim, este trabalho acadêmico também se propõe a avaliar a aderência de premissas envolvendo metodologias como o Activity Based Budgeting, o Balanced Scorecard, e o Beyond Budgeting.

\section{Referencial teórico}

\subsection{A importância de um modelo de planejamento e controle}

Planejamento e controle são funções que integram o processo administrativo para os principais autores clássicos e neoclássicos, de acordo com Chiavenato (1983). Já Welsch et al. (1988) apontam duas visões conceituais distintas sobre o papel do gerenciamento: A Teoria do Mercado e a Teoria do Planejamento e Controle. Na Teoria do Mercado o papel do gerenciamento é passivo, ou seja, as decisões são de caráter reativo, respondendo aos eventos no ambiente, na medida em que os mesmos ocorrem. Já na Teoria do Planejamento e Controle ocorre justamente o inverso, passando o gerenciamento a assumir um papel ativo. Nesta teoria acredita-se que o fator primário de sucesso numa empresa é a competência com que se gerencia o planejamento e controle das atividades empresariais.

Em que pese a ressalva feita por Welsch et al. (1988) de que no mundo real a gerência opera entre estes dois extremos conceituais, os autores se posicionam claramente a favor da segunda teoria, entendendo ser o planejamento e o controle as duas funções primárias dos gerentes numa entidade, e ressaltando o aspecto de que a efetividade com a qual uma entidade é gerenciada pode ser reconhecida como o fator mais importante no sucesso de longo prazo. Os referidos autores argumentam ainda que a responsabilidade essencial dos gestores é manipular, por meio do processo de gerenciamento, as combinações planejadas de entradas e saídas para que os objetivos organizacionais de longo prazo possam ser atingidos.

Oliveira in Catelli (2001) chama a atenção para o fato de que alguns autores não distinguem o planejamento do controle, uma vez que entendem que a gestão é um grande processo de controle sobre os rumos de uma organização. Esta relação é reforçada pela afirmação de Frezatti (2000) de 
que se o planejamento é inadequado, o controle é inócuo. Para Ackoff (1994) apud Frezatti (2000) planejar significa decidir antecipadamente. A idéia de decisão antecipada proposta por Ackoff também é a essência do conceito de planejamento apontada por Welsch et al. (1988) e corroborada por Sanvicente e Santos (2000), por meio do uso das expressões "desenvolvimento de objetivos organizacionais e a seleção de um futuro plano de ações para atendê-los" e "estabelecimento com antecedência das ações a serem executadas", citadas respectivamente.

Welsch (1994 apud FREZATTI, 2000) trata de apontar uma série de motivos pelos quais é vantajoso o processo de planejamento, com base na essência da definição proposta por Ackoff, de que planejar significa decidir antecipadamente: (1) coordenação de atividades (impossível coordenar atividades sem algum nível de planejamento prévio); (2) decisões antecipadas (tempo para pensar e amadurecer uma decisão); (3) comprometimento a priori (metas estabelecidas conjuntamente passam a ser buscadas); (4) possibilidade de maior transparência (se o orçamento for participativo, diversas áreas trabalham e discutem juntas); (5) definição de responsabilidades (cobrança de resultados); (6) destaque para a eficiência (níveis de desempenho adequados devem ser perseguidos; desempenho inadequado é evitado na fase de planejamento); (7) possibilidade de maior entendimento mútuo (transparência entre as etapas); (8) força a auto-análise (auto-análise frente aos desafios vindouros); (9) permite a avaliação do progresso (não se basear apenas no referencial passado).

Frezatti (2000) complementa que a capacidade de se antecipar uma decisão é um fator de distinção entre as empresas. Esta importância dada por Frezatti ao planejamento já havia sido anteriormente destacada por Rappaport (2001) in Montgomery e Porter (1998), quando o mesmo se referia ao sistema formal de planejamento estratégico. Para ele, num ambiente de negócios mutável e freqüentemente desconcertante, os sistemas formais de planejamento estratégico tornaram-se uma das principais ferramentas da alta gerência para avaliar e enfrentar as incertezas.

Para Welsch et al. (1988), controle pode ser definido como o processo de medição e avaliação da performance real de cada componente organizacional de uma empresa, e implementação de ações corretivas quando necessárias para assegurar a eficiência no alcance dos objetivos organizacionais, metas, políticas e padrões. Sanvicente e Santos (2000) ratificam plenamente esta conceituação ao definir controle como sendo o acompanhamento da execução de atividades que visa comparar o desempenho efetivo com o que havia sido planejado (originalmente considerado desejável, satisfatório ou viável para a empresa e suas sub-unidades), devendo gerar informações para a tomada de decisões e correção do desempenho.

\subsection{O modelo tradicional de planejamento e controle}


Um modelo tradicional de planejamento e controle dos lucros deve conter alguns elementos mínimos que permitam a sua caracterização. Welsch et al. (1988) afirmam que para que um método de planejamento e controle possa ser caracterizado como completo, é necessário que haja uma abordagem sistemática e formal de execução das diferentes e significativas fases do planejamento gerencial e controle. Estas fases envolvem: (1) desenvolvimento e aplicação de amplos objetivos de longo prazo para a empresa; (2) especificação das metas da empresa; (3) desenvolvimento de um amplo e estratégico plano de lucros de longo prazo; (4) um plano de lucros de curto prazo definido por centro de responsabilidade; (5) um sistema para periódico reporte da performance detalhado por centro de responsabilidade; (6) o acompanhamento dos procedimentos.

Frezatti (2000), embora entendendo que cada organização possua seu próprio modelo de planejamento e controle, afirma que os mecanismos de planejamento estratégico, orçamento anual e controle orçamentário devem estar presentes como instrumentos mínimos num modelo tradicional de planejamento e controle, corroborando assim o entendimento dos autores Welsch et al. (1988). Especificando um pouco mais cada um desses três elementos chave (planejamento estratégico, orçamento e anual e controle orçamentário), Welsch et al. (1988) definiram os diversos componentes de um programa típico de planejamento e controle dos lucros. Existem dois planos básicos no programa: Plano Substantivo (objetivos amplos, estratégias, planos específicos e programas executivos/premissas) e Plano Financeiro.

Tendo como base este modelo, pode-se claramente perceber que um programa de planejamento e controle de lucros inclui mais do que a idéia tradicional de um orçamento, cuja imagem está mais fortemente associada exclusivamente ao Plano Financeiro. Num modelo tradicional e efetivo de planejamento e controle dos lucros, uma ênfase muito grande é dada ao Plano Substantivo. Para os autores supracitados, a fundação de um modelo tradicional de planejamento e controle envolve a definição de objetivos organizacionais amplos (missão, visão e características éticas da organização; não devem especificar objetivos quantitativos), a definição de metas organizacionais específicas (metas narrativas e quantitativas de longo e de curto prazos, metas operacionais), e o desenvolvimento e avaliação das estratégias organizacionais (táticas que serão adotadas para que se atinjam os objetivos - focam em como, e por isso geram planos de ação).

Para Frezatti (2000) o orçamento só pode ser preparado quando um plano estratégico tiver sido elaborado prévia e adequadamente. Este é um pressuposto básico para que o orçamento tenha coerência e consistência. De acordo com Rappaport (2001) e Montgomery e Porter (1998), embora a dinâmica organizacional e a sofisticação do processo de planejamento estratégico variem muito entre as empresas, o processo quase que invariavelmente culmina na projeção de resultados financeiros, pois esta projeção serve geralmente como base para a análise da atratividade da estratégia ou do planejamento corporativo de longo prazo. Em um modelo tradicional, o 
planejamento e o controle estão fortemente ligados, e devem se estender por todas as áreas numa organização, havendo maior foco de planejamento na alta administração e maior foco de controle em finanças.

\subsection{As críticas ao modelo tradicional}

Não se pode contestar o fato de que grande parte das empresas desenvolve algum mecanismo de planejamento e controle em suas operações cotidianas. Entretanto cada vez mais se questiona a validade de um planejamento orçamentário nos moldes tradicionais, principalmente nos casos onde este possui relação ou até desencadeia algum tipo de programa de bonificação aos funcionários.

São vários os motivos pelos quais o processo orçamentário vem sendo sistematicamente questionado. Welsch et al. (1988) apontam alguns argumentos freqüentemente utilizados contra um modelo tradicional de planejamento e controle dos lucros: (1) é difícil ou mesmo impossível estimar receitas e despesas de maneira realista; (2) um sistema informal é melhor e funciona bem; (3) não é realista escrever e distribuir metas, políticas e orientações para todos os supervisores; (4) orçamentos requerem um dispêndio de tempo muito grande por parte da gerência, especialmente nas constantes revisões; (5) tiram a flexibilidade gerencial; (6) criam todos os tipos de problemas comportamentais; (7) colocam os gerentes em camisas de força; (8) adicionam um nível de complexidade que não é necessário. Desde que Welsch et al. (1988) apontaram estes argumentos contrários a um modelo tradicional de planejamento e controle dos lucros, as críticas vêm se tornando cada vez mais freqüentes e contundentes por parte não só de executivos como também no meio acadêmico.

Leahy (2002) cita uma pesquisa realizada durante o primeiro trimestre de 2001 pelo Centro para o Desempenho dos Negócios da Cranfield University School Of Management, e pela firma de consultoria Accenture. De acordo com o resultado das entrevistas pessoais com executivos de quinze multinacionais, foram identificadas doze queixas mais comuns sobre as abordagens tradicionais de planejamento e controle: (1) quase nunca dão suporte às estratégias da empresa e, na verdade, muitas vezes as contradizem; (2) exigem um processo que não agrega valor; (3) concentram-se na redução de custos e não no aumento de valor; (4) fortalecem comando e controle verticais dentro de uma organização; (5) não refletem iniciativas emergentes, como as novas estruturas de rede que as empresas estão adotando; (6) estimulam o uso de estratégias com interesses puramente individuais e comportamentos perversos; (7) são elaborados e atualizados com freqüência insuficiente; (8) baseiam-se em hipóteses sem fundamento e palpites; (9) reforçam barreiras entre departamentos em vez de estimularem que o conhecimento seja compartilhado; (10) 
fazem com que as pessoas se sintam desvalorizadas; (11) consomem muito tempo e (12) tiram a flexibilidade grencial. Ainda de acordo com Leahy (2002), a maior parte das empresas continua adotando basicamente os mesmos métodos de sempre na preparação dos seus orçamentos.

Fisher (2002) revela que uma pesquisa conduzida pela empresa de consultoria Comshare, em fevereiro de 2000, indicou que 94\% dos profissionais seniores de finanças estavam frustrados com o processo orçamentário nas suas organizações. A maioria disse que o tempo para preparação era o principal problema, e outros disseram que se sentiam paralisados em virtude da tecnologia disponível. Para esta autora, a opinião de que o budget tradicional está desatualizado e precisa mudar é crescente. Libby e Lindsay (2003) ressaltam que diversas empresas da Europa ou abandonaram ou estão abandonando o seu processo de orçamento, nas quais pesquisas recentes retratam crescente insatisfação entre as organizações com o seu processo orçamentário. As autoras abordam os estudos conduzidos pelo movimento conhecido por "BBRT - Beyond Budgeting Roundtable" (um programa do "Consortium for Advanced Manufacturing International"), que segundo elas está ganhando cada vez mais notoriedade. Argumentam que no modelo tradicional opera-se no top down de comando e controle. Decisões, recursos e recompensas vão de cima para baixo, enquanto a informação vem de baixo para cima.

Em que pese à relevância da discussão acerca dos questionamentos ora mencionados por diferentes autores, talvez a mais preocupante crítica relaciona-se ao fato de que o processo orçamentário pode vir a se tornar um importante obstáculo à criação e à maximização de valor aos acionistas. Jensen (2001) afirma que um conflito de agência se estabelece sempre que houver associação do orçamento a um plano de bonificação aos funcionários, sendo que o referido orçamento passa a estar contaminado por interesses conflitantes entre acionistas e administradores. Nestes casos o orçamento não apenas perde a sua principal finalidade, que é a de prover a base para boas decisões de negócio e possibilitar a efetiva coordenação das ações do dia a dia, como também contribui para que haja erosão de valor na organização.

\subsection{As alternativas ao modelo tradicional}

Orçamento Baseado em Atividades - $\boldsymbol{A B B}$ : Uma das alternativas mais conhecidas ao modelo tradicional de planejamento e controle de lucros é o chamado Orçamento Baseado em Atividades - $A B B$. Para Brimson e Antos (1999) esta metodologia foi concebida com o objetivo de que houvesse um maior foco na criação de valor, no que se refere ao processo de planejamento e controle. Em essência, busca-se traduzir a estratégia do negócio em atividades necessárias para implantação da mesma, pois não apenas ajuda os gerentes a entender onde o dinheiro está sendo gasto, mas também ajuda entender qual trabalho eles esperam realizar. Neste método, o foco está 
não nos recursos, mas sim nas atividades. Os referidos autores destacam os seguintes benefícios de um orçamento baseado em atividades: (1) estabelece responsabilidade para os funcionários para gerenciarem suas atividades de forma a atingirem as metas de performance; (2) apresenta uma visão mais realista da carga de trabalho incluindo o impacto do nível de serviços; (3) provê habilidade para entender como os produtos e serviços criam demanda de atividades específicas que por sua vez requerem recursos; (4) implanta uma visão de processo que ilustra mais explicitamente as interdependências departamentais; (5) cria a habilidade para monitorar e controlar num nível mais interativo; (6) provê visibilidade no excesso ou insuficiência de capacidade gerencial.

Balanced Scorecard: A metodologia introduzida com o conceito do Balanced Scorecard objetiva preencher uma lacuna do processo tradicional de planejamento e controle, por meio do adequado e necessário gerenciamento da estratégia organizacional. Com o uso desta ferramenta, as organizações passam a relacionar a estratégia ao seu processo tradicional de planejamento e controle dos lucros (orçamento). Kaplan e Norton (2001) esclarecem que o Balanced Scorecard foi originalmente proposto para superar as limitações do gerenciamento com base apenas em medidas financeiras, já que um plano estratégico substitui o budget como o centro do processo de gerenciamento. O Balanced Scorecard provê uma estrutura para se olhar à estratégia, do ponto de vista da criação de valor, considerando quatro diferentes perspectivas: (1) financeira - estratégia para crescimento, lucratividade e risco, vista da perspectiva dos acionistas; (2) cliente - estratégia para criação de valor e diferenciação, vista da perspectiva do cliente; (3) processos internos prioridades estratégicas dos vários processos do negócio, que criam satisfação para acionistas e clientes; (4) aprendizagem e crescimento: prioridades que criam um clima que suporte mudanças organizacionais, inovação e crescimento.

Better Budgeting, Global Budgeting e Rolling Forecasts: Para Neumann (2001) a idéia do Global Budgeting envolve "o menos é mais". O conceito geral é que os gerentes encontrarão um documento fácil de ler e fácil de usar. Qualquer orçamento pode se tornar um global budgeting. Para tal deve-se obter um formato tradicional e simplificá-lo num formato mais compreensível (racionalização/agrupamento das despesas e das receitas). Fisher (2002) sugere uma metodologia alternativa chamada de Better Budgeting. Este método consiste na análise detalhada do processo orçamentário, com vistas à eliminação de inconsistências e ineficiências. Trata-se, portanto, de uma reengenharia do processo orçamentário, objetivando torná-lo mais ágil e adequado à realidade dos dias atuais. Howell (2004) sugere a introdução de rollilng forecats para um período maior do que um ano, como forma de que os gerentes tenham em vista um horizonte mais distante e mais relacionado a decisões estratégicas de investimentos. Propõe ainda que o formato do budget seja alterado de forma a enfatizar mais o aspecto geração de caixa em detrimento ao aspecto do lucro contábil. 
Beyond Budgeting: Hope e Fraser (2003) acreditam que dadas às características de negócio nos dias atuais, o modelo tradicional de planejamento e controle - budgeting - não deve ser melhorado, mas sim abandonado inteiramente. Os autores propõem um modelo gerencial alternativo que envolve um conjunto de novos processos propiciando o surgimento de metas de natureza relativa, planejamento contínuo, recursos ligados à demanda e coordenação dinâmica, entre outros aspectos. Trata-se de um modelo coerente que envolve uma série de processos alternativos, e que tem como resultado a transferência da responsabilidade pela performance de um nível centralizado para os gerentes operacionais. O modelo Beyond Budgeting vem sendo usado em dois diferentes níveis de extensão, dependendo de como as empresas queiram implementá-lo. Em alguns casos opta-se por uma adaptação do processo (que possibilita aos gerentes focarem na criação contínua de valor) e em outros numa descentralização radical (que possibilita aos líderes criarem uma organização de alta performance).

\section{Procedimentos metodológicos}

O objetivo principal do presente estudo é procurar estabelecer uma correlação entre a existência de um programa sistemático de planejamento e controle, e o desempenho financeiro superior de uma empresa, do ponto vista operacional. Paralelamente também se buscou verificar outros três aspectos: (1) se as empresas pesquisadas adotam algum programa sistemático de planejamento e controle dos lucros; (2) se o método tradicional de planejamento e controle dos lucros ainda vem sendo utilizado nas empresas pesquisadas, ou, se já há aderência de métodos alternativos (Activity Based Budgeting, Balanced Scorecard, e Beyond Budgeting), (3) o nível de satisfação das empresas pesquisadas em relação ao seu processo orçamentário.

Para que tais objetivos sejam atendidos, foi conduzida uma pesquisa de campo do tipo exploratória / descritiva, com a aplicação de questionários, tendo sido definido como população alvo, companhias brasileiras de capital aberto, com fins lucrativos, e pertencentes a qualquer segmento de atividade econômica, exceção feita ao segmento financeiro. Dada à natureza do problema de pesquisa, e devido ao fato de existirem aspectos exploratórios, a opção foi pela seleção de uma amostragem por julgamento, não probabilística. Conseqüentemente, não houve nenhuma estimativa de erro amostral. A população-alvo desta pesquisa envolveu um universo de 250 companhias, sendo que destas, 45 empresas atenderam ao convite de responder ao questionário. $\mathrm{O}$ estudo envolveu a coleta de dados primários e de dados secundários. Os dados primários foram obtidos com a utilização de um questionário composto de 54 perguntas, sendo 5 delas direcionadas para identificação do respondente. 
Das demais perguntas, haviam 25 perguntas fechadas e de múltipla escolha (sim, não, não sei / não quero responder) visando avaliar a prática dos procedimentos tradicionais de planejamento e controle por parte das empresas; 11 perguntas fechadas e de múltipla escolha visando avaliar a aderência de metodologias alternativas de planejamento e controle (uma das alternativas possibilitava ao respondente descrever uma eventual metodologia divergente das descritas nas opções anteriores); e 13 perguntas fechadas e de múltipla escolha (sim, não, não sei / não quero responder) visando avaliar o grau de satisfação das empresas em relação aos seus mecanismos de planejamento e controle. Em se tratando dos dados secundários, os mesmos foram obtidos da base Economática $^{\circledR}$, e envolveram as seguintes informações financeiras, relacionadas aos anos de 2001 a 2003: (a) Ebit , (b) Capital empregado, (c) Total dos Ativos. O tratamento dos dados seguiu o modelo de estudo proposto por Farragher, Kleiman e Sahu (2001), que pesquisaram a relação existente entre um modelo sofisticado de orçamento de capital e uma performance financeira superior. Para tal foram aplicadas técnicas estatísticas de análise multivariada.

No presente estudo houve apenas uma variável dependente (Retorno sobre o Capital Empregado), e por essa razão a técnica utilizada para o tratamento estatístico dos dados foi a regressão múltipla. Seguindo a estrutura proposta por Farragher, et al. (2001), neste estudo foi estimado o seguinte modelo de regressão múltipla objetivando associar a performance financeira das empresas, a um programa sistemático de planejamento e controle:

$$
R O C E_{j}=\beta_{0}+\beta_{1} S P O+\beta_{2} T E_{j}+\beta_{3} I C_{j}+\beta_{4} R O_{j}
$$

Onde:

$R O C E j=$ Retorno sobre o Capital Empregado da empresa em relação ao segmento em que atua;

$S P O=$ Grau de Sofisticação do Planejamento Orçamentário;

$T E j$ = Tamanho da empresa em relação ao segmento em que atua;

$I C j=$ Intensidade de Capital da empresa em relação ao segmento em que atua;

$R O j=$ Risco Operacional da empresa em relação ao segmento em que atua.

No que se refere à variável independente (Existência de um Programa Sistemático de Planejamento e Controle), com base na literatura pesquisada, foram selecionados 25 procedimentos característicos de um programa sistemático de planejamento e controle. Estes procedimentos foram submetidos à avaliação de um grupo composto por três pessoas, sendo duas delas professores acadêmicos de comprovado renome e experiência em relação ao assunto em questão. A missão deste pequeno comitê foi a de ponderar os 25 procedimentos obtidos na literatura, atribuindo notas numa escala de 1 a 5 (sendo 5 um procedimento tido como de alta relevância no contexto de um 
programa sistemático de planejamento e controle, e 1 um procedimento de menor relevância). De acordo com a opinião do comitê, os quatro principais procedimentos de um programa sistemático de planejamento e controle são: (1) Comprometimento da Alta Administração; (2) Sistemática de Reporte Periódico de Real versus Orçado; (3) Realização de um Budget de curto prazo; (4) Budget derivando do Planejamento Estratégico.

Para a variável dependente, a medida de valor adotada neste estudo foi o Retorno sobre o Capital Empregado - ROCE. O ROCE ou ROIC é reconhecidamente uma medida válida de mensuração da rentabilidade operacional das empresas, já que avalia a relação existente entre a capacidade de geração do lucro operacional de uma empresa (EBIT) com a necessidade de recursos alocados para tal (capital empregado). O ROCE também pode ser calculado por meio da multiplicação da Margem Operacional pelo Giro dos Ativos. Todos os dados, após terem sido tratados, foram introduzidos no programa estatístico SPSS, para que se pudesse empregar a técnica de regressão múltipla em relação às variáveis descritas.

\section{Resultados}

As empresas que adotam um programa sistemático de planejamento e controle dos lucros apresentam, no médio e longo prazo, um resultado financeiro operacional superior no segmento em que atuam? Esta hipótese não se confirmou, na medida em que estatisticamente não foi evidenciada uma relação de causa e efeito entre essas duas variáveis. Algumas tentativas foram feitas buscandose evidenciar esta correlação, por intermédio da interpretação das variáveis em diferentes tratamentos. Contudo a esperada relação de dependência não foi caracterizada. Por outro lado, pôde-se constatar uma relação estatística significante das variáveis independentes "RO - Risco Operacional" e "TE - Tamanho da Empresa com a variável dependente "ROCE", o que vem a corroborar as afirmações de Jacquemin e Saez (1976) e Klammer (1973) apud Farragher et al. (2001), cujos estudos evidenciaram que negócios de alto risco tendem a apresentar retornos financeiros mais altos, bem como que o tamanho de uma empresa (medido por meio do valor de seus ativos) é positivamente relacionado à sua performance financeira.

A falta de evidência de uma relação direta de dependência entre planejamento e controle com um resultado financeiro operacional superior, de maneira alguma descaracteriza a importância destas funções administrativas, já que mesmo as maiores críticas sempre são relacionadas à forma como estas atividades são conduzidas e o que se espera delas, mas nunca sugerindo o total abandono das mesmas: 
a) O processo orçamentário falhou (inclusive por não inspirar as pessoas), porém sua importância é reconhecida, sendo esse talvez o único esforço para o estabelecimento de objetivos extensivos em muitas empresas (SMITH, 2000);

b) As empresas devem adotar uma nova metodologia de planejamento estratégico, mas o budgeting é fundamental no gerenciamento tático de uma organização (KAPLAN; NORTON, 2001);

c) O problema não está no programa, mas sim na forma como ele possa vir a ser utilizado (WELSCH et al., 1988);

d) Os orçamentos corporativos é uma piada. Encorajam os gerentes a mentir e a enganar. Contudo, a chave está não na destruição do sistema orçamentário, mas na mudança na maneira como as organizações pagam as pessoas. O processo orçamentário por si só não é a causa das ações contra-produtivas, mas sim o uso do orçamento para determinar recompensas (JENSEN, 2001);

e) O modelo tradicional de budeting deve ser abandonado, contudo deve ser adotada uma nova sistemática onde também existam mecanismos de planejamento e controle (HOPE; FRASER, 2003).

Sendo assim, a não confirmação da hipótese de pesquisa não questiona a validade das atividades de planejamento e controle. Apenas não caracteriza uma relação direta de tais atividades e um resultado financeiro superior nas empresas, o que pode vir a corroborar o pensamento de Hope e Fraser (2003), segundo o qual uma performance superior não é direcionada por planos e controles. Tung (1994), que embora defenda veementemente o uso de um modelo de planejamento e controle, já havia alertado que nem sempre a implantação do sistema orçamentário leva a empresa, necessariamente, a bons resultados financeiros. Todavia, o fato de uma relação de dependência não ter sido evidenciada também pode, eventualmente, ser decorrente de limitações do presente estudo, como por exemplo, o tamanho da amostra (não probabilística).

Demais resultados puderam ser abstraídos do presente estudo, entre eles o fato de que a maioria das empresas utiliza procedimentos sistemáticos de planejamento e controle. Tal resultado, não corrobora as evidências de Libby e Lindsay (2003) para as empresas européias, em que diversas empresas já teriam abandonado seu processo orçamentário.

Foi apurado que todas as empresas pesquisadas adotam no mínimo 12 dos 25 procedimentos de planejamento e controle mais citado na literatura, sendo que $29 \%$ delas praticam todos os vinte e cinco. Pelo menos 1 destes 25 procedimentos vem sendo utilizado por alguma das empresas pesquisadas, no qual o grau e adesão de cada um deles é de no mínimo 78\%, conforme demonstrado na Tabela 1: 
Tabela 1 - Procedimentos de planejamento e controle praticados

\begin{tabular}{|c|c|c|c|c|c|c|c|c|}
\hline \multicolumn{2}{|r|}{ Procedimentos de Planejamento e Controle } & \multicolumn{7}{|c|}{ Empresas Pesquisadas } \\
\hline $\mathbf{N}^{\mathbf{0}}$ & Breve Descrição & \multicolumn{2}{|c|}{$\begin{array}{l}\text { Praticam/ } \\
\text { Possuem }\end{array}$} & \multicolumn{2}{|c|}{$\begin{array}{l}\text { Não Praticam/ } \\
\text { Possuem }\end{array}$} & \multicolumn{2}{|c|}{$\begin{array}{c}\text { Não } \\
\text { Sabem }\end{array}$} & \multirow{2}{*}{$\begin{array}{c}\text { Total } \\
45\end{array}$} \\
\hline 1 & Divulgação da missão organizacional & 44 & $98 \%$ & 1 & $2 \%$ & 0 & $0 \%$ & \\
\hline 2 & Metas de longo prazo & 37 & $82 \%$ & 7 & $16 \%$ & 1 & $2 \%$ & 45 \\
\hline 3 & Estratégias para longo prazo & 41 & $91 \%$ & 3 & $7 \%$ & 1 & $2 \%$ & 45 \\
\hline 4 & Planos de ação com base estratégica & 38 & $84 \%$ & 4 & $9 \%$ & 3 & $7 \%$ & 45 \\
\hline 5 & Plano financeiro de longo prazo $3 / 5$ anos & 35 & $78 \%$ & 9 & $20 \%$ & 1 & $2 \%$ & 45 \\
\hline 6 & Plano financeiro de curto prazo 1 ano & 43 & $96 \%$ & 2 & $4 \%$ & 0 & $0 \%$ & 45 \\
\hline 7 & Plano de curto prazo derivando do PE & 40 & $89 \%$ & 4 & $9 \%$ & 1 & $2 \%$ & 45 \\
\hline 8 & Suporte da alta administração & 42 & $93 \%$ & 1 & $2 \%$ & 2 & $4 \%$ & 45 \\
\hline 9 & Budget desafiador mas atingível & 43 & $96 \%$ & 2 & $4 \%$ & 0 & $0 \%$ & 45 \\
\hline 10 & Budget com base em premissas básicas & 45 & $100 \%$ & 0 & $0 \%$ & 0 & $0 \%$ & 45 \\
\hline 11 & Manual para preparação do Budget & 43 & $96 \%$ & 2 & $4 \%$ & 0 & $0 \%$ & 45 \\
\hline 12 & Estrutura contábil adequada & 44 & $98 \%$ & 1 & $2 \%$ & 0 & $0 \%$ & 45 \\
\hline 13 & Análise de sensibilidade durante processo & 37 & $82 \%$ & 7 & $16 \%$ & 1 & $2 \%$ & 45 \\
\hline 14 & Comunicação adequada aos envolvidos & 43 & $96 \%$ & 2 & $4 \%$ & 0 & $0 \%$ & 45 \\
\hline 15 & Budget utilizado para alocação de recursos & 42 & $93 \%$ & 2 & $4 \%$ & 1 & $2 \%$ & 45 \\
\hline 16 & Budget utilizado com flexibilidade & 39 & $87 \%$ & 6 & $13 \%$ & 0 & $0 \%$ & 45 \\
\hline 17 & Budget revisado no ano (forecasts) & 35 & $78 \%$ & 10 & $22 \%$ & 0 & $0 \%$ & 45 \\
\hline 18 & Revisões acontecem sempre que necessário & 38 & $84 \%$ & 6 & $13 \%$ & 1 & $2 \%$ & 45 \\
\hline 19 & Sistemática report performance financeira & 43 & $96 \%$ & 1 & $2 \%$ & 1 & $2 \%$ & 45 \\
\hline 20 & Sistemática report performance operacional & 42 & $93 \%$ & 1 & $2 \%$ & 2 & $4 \%$ & 45 \\
\hline 21 & Relatórios atendem às expectativas & 39 & $87 \%$ & 5 & $11 \%$ & 1 & $2 \%$ & 45 \\
\hline 22 & Variações são analisadas e compreendidas & 44 & $98 \%$ & 0 & $0 \%$ & 1 & $2 \%$ & 45 \\
\hline 23 & Ações corretivas são adotadas & 41 & $91 \%$ & 2 & $4 \%$ & 2 & $4 \%$ & 45 \\
\hline 24 & Informações oportunas e confiáveis & 42 & $93 \%$ & 2 & $4 \%$ & 1 & $2 \%$ & 45 \\
\hline 25 & Dados atualizados & 35 & $78 \%$ & 8 & $18 \%$ & 2 & $4 \%$ & 45 \\
\hline
\end{tabular}

Fonte: Elaborada pelos autores (2009).

A partir deste estudo, também foi possível concluir que a maior parte dos procedimentos de planejamento e controle estão relacionados à metodologia tradicional. Pode-se notar que todas as empresas pesquisadas já utilizam, em maior ou menor grau, alguns métodos alternativos ligados aos modelos do Activity Based Budgeting, Balanced Scorecard, e Beyond Budgeting. A Tabela 2, abaixo, demonstra que cerca de $30 \%$ dos procedimentos de planejamento e controle estão vinculados a uma metodologia alternativa. Existem três aspectos, em que o método conservador não vem mais sendo aplicado na maior parte das empresas 1) coordenação das ações; 2) foco dado ao monitoramento estratégico e 3) planejamento na alocação dos recursos.

Tabela 2 - Método tradicional versus alternativo nas empresas pesquisadas

\begin{tabular}{c|cc|ccccc}
\hline \multirow{2}{*}{ Aspectos do Planejamento e Controle } & \multicolumn{5}{c|}{ Método Utilizado- Qtde de Empresas } & \multicolumn{2}{c}{$\begin{array}{c}\text { Total } \\
\text { Empresas }\end{array}$} \\
\cline { 2 - 6 } & Tradicional & Alternativo & \multicolumn{2}{c}{ Ambos } & $4 \%$ \\
\hline Estabelecimento de metas & 37 & $82 \%$ & 6 & $13 \%$ & 2 & $4 \%$ & 45 \\
\hline Sistema de recompensas & 35 & $78 \%$ & 10 & $22 \%$ & 0 & $0 \%$ & 45 \\
\hline Periodicidade do Planejamento das ações & 36 & $80 \%$ & 8 & $18 \%$ & 1 & $2 \%$ & 45 \\
\hline Responsáveis pelo Planej. das ações estratégicas & 34 & $76 \%$ & 5 & $11 \%$ & 6 & $13 \%$ & 45 \\
\hline Gerenciamento dos recursos & 30 & $67 \%$ & 12 & $27 \%$ & 3 & $7 \%$ & 45 \\
\hline Coordenação das ações & 17 & $38 \%$ & 28 & $62 \%$ & 0 & $0 \%$ & 45 \\
\hline Mensuração e controle da performance & 41 & $91 \%$ & 2 & $4 \%$ & 2 & $4 \%$ & 45 \\
\hline Planejamento na alocação dos recursos & 18 & $40 \%$ & 26 & $58 \%$ & 1 & $2 \%$ & 45 \\
\hline
\end{tabular}




\begin{tabular}{cccccccc}
\hline Produto final do processo Orçamentário & 22 & $49 \%$ & 22 & $49 \%$ & 1 & $2 \%$ & 45 \\
\hline Foco dado ao monitoramento estratégico & 17 & $38 \%$ & 28 & $62 \%$ & 0 & $0 \%$ & 45 \\
\hline Freqüência do Planejamento estratégico & 44 & $98 \%$ & 1 & $2 \%$ & 0 & $0 \%$ & 45 \\
\hline Total de Citações & $\mathbf{3 3 1}$ & $\mathbf{6 7 \%}$ & $\mathbf{1 4 8}$ & $\mathbf{3 0 \%}$ & $\mathbf{1 6}$ & $\mathbf{3 \%}$ & $\mathbf{4 9 5}$ \\
\hline
\end{tabular}

Fonte: Elaborada pelos autores (2009).

Por fim, este estudo também revelou que as empresas pesquisadas não demonstraram descontentamento em relação aos seus programas de planejamento e controle. Ao contrário, apenas $12 \%$ das respostas confirmam as principais queixas abordadas na literatura. A posição apurada, mais uma vez não corrobora Libby e Lindsay (2003), que indicam pesquisas recentes retratando crescente insatisfação entre as organizações com o seu processo orçamentário.

Vale ressaltar que talvez a razão pela qual a maioria das empresas esteja satisfeita com os seus procedimentos de planejamento e controle seja o fato de que foi constatada uma introdução gradual de procedimentos alternativos, já tendo sido desprezados alguns aspectos relacionados ao método tradicional que eventualmente poderiam estar desagradando a estas mesmas empresas (Tabela 3):

Tabela 3 - Grau de satisfação das empresas com seu planejamento e controle

\begin{tabular}{|c|c|c|c|c|c|c|c|}
\hline \multirow{3}{*}{$\begin{array}{l}\text { Queixas mais freqüentes apontadas na } \\
\text { literatura } \\
\text { O processo orçamentário absorve muito tempo } \\
\text { levando-se em consideração um benefício incerto. }\end{array}$} & \multicolumn{7}{|c|}{ Quantidade de empresas } \\
\hline & \multicolumn{2}{|c|}{ Sim } & \multicolumn{2}{|c|}{ Não } & \multicolumn{2}{|c|}{ Não sei } & \multirow{2}{*}{$\begin{array}{c}\text { Total } \\
45\end{array}$} \\
\hline & 8 & $18 \%$ & 36 & $80 \%$ & 1 & $2 \%$ & \\
\hline O processo orçamentário é incomodo. & 6 & $13 \%$ & 37 & $82 \%$ & 2 & $4 \%$ & 45 \\
\hline $\begin{array}{l}\text { O processo orçamentário está ultrapassado em } \\
\text { relação ao ambiente competitivo. }\end{array}$ & 2 & $4 \%$ & 40 & $89 \%$ & 3 & $7 \%$ & 45 \\
\hline $\begin{array}{l}\text { É difícil senão impossível estimar receitas e } \\
\text { despesas de maneira realista. }\end{array}$ & 3 & $7 \%$ & 42 & $93 \%$ & 0 & $0 \%$ & 45 \\
\hline $\begin{array}{l}\text { O orçamento restringe excessivamente a } \\
\text { flexibilidade gerencial, agindo como uma "camisa } \\
\text { de força". }\end{array}$ & 1 & $2 \%$ & 43 & $96 \%$ & 1 & $2 \%$ & 45 \\
\hline $\begin{array}{l}\text { O orçamento adiciona um nível de complexidade } \\
\text { que não é necessário. }\end{array}$ & 3 & $7 \%$ & 41 & $91 \%$ & 1 & $2 \%$ & 45 \\
\hline $\begin{array}{l}\mathrm{O} \text { orçamento rapidamente fica desatualizado, } \\
\text { perdendo desta forma sua finalidade. }\end{array}$ & 2 & $4 \%$ & 42 & $93 \%$ & 1 & $2 \%$ & 45 \\
\hline $\begin{array}{l}\text { O processo orçamentário é muito mais um } \\
\text { exercício político do que estratégico. }\end{array}$ & 2 & $4 \%$ & 40 & $89 \%$ & 3 & $7 \%$ & 45 \\
\hline $\begin{array}{l}\text { O processo orçamentário concentra-se na redução } \\
\text { de custos e não no aumento de valor. }\end{array}$ & 8 & $18 \%$ & 36 & $80 \%$ & 1 & $2 \%$ & 45 \\
\hline $\begin{array}{l}\text { O processo orçamentário fortalece uma estrutura de } \\
\text { comando e controle vertical. }\end{array}$ & 16 & $36 \%$ & 24 & $53 \%$ & 5 & $11 \%$ & 45 \\
\hline $\begin{array}{l}\text { Pelo fato da remuneração variável estar atrelada á } \\
\text { capacidade de se alcançar níveis previstos no } \\
\text { orçamento, existe alta incidência de manipulação } \\
\text { do mesmo. }\end{array}$ & 1 & $2 \%$ & 41 & $91 \%$ & 3 & $7 \%$ & 45 \\
\hline $\begin{array}{l}\mathrm{Na} \text { empresa utilizam-se ferramentas e tecnologias } \\
\text { inapropriadas, que dificultam a preparação do } \\
\text { orçamento. }\end{array}$ & 9 & $20 \%$ & 35 & $78 \%$ & 1 & $2 \%$ & 45 \\
\hline $\begin{array}{l}\text { O orçamento não está explicitamente conectado } \\
\text { com a implementação das estratégias. }\end{array}$ & 9 & $20 \%$ & 33 & $73 \%$ & 3 & $7 \%$ & 45 \\
\hline Média & 5 & & 38 & & 2 & & 45 \\
\hline \% de Representatividade & & $12 \%$ & & $84 \%$ & & $4 \%$ & $100 \%$ \\
\hline
\end{tabular}

Fonte: Elaborada pelos autores (2009). 


\section{Considerações finais}

Um dos assuntos mais tradicionais no campo da Administração é o Planejamento e Controle. Não obstante haver algumas divergências sobre a utilidade desta ferramenta de gestão, tal assunto vem recebendo diversas contribuições teóricas e práticas. De acordo com os resultados apresentados neste trabalho, a maioria das empresas pesquisadas adota o Planejamento e Controle no método tradicional, embora já se observe uma importância dos métodos alternativos.

O Orçamento, peça integrante do Planejamento e Controle, é adotado em todas as empresas pesquisadas, o que evidencia a importância deste instrumento, ainda mais se considerar a relativa instabilidade do ambiente de negócios no Brasil.

De forma geral, as empresas estão satisfeitas com o seu Planejamento e Controle, revelando que a falta deste poderia prejudicar, sobremaneira, a tomada de decisão dos gestores. Os métodos alternativos vêm dando um novo fôlego às práticas empresariais, aprimorando o Planejamento Estratégico como um todo. Em um ambiente cada vez mais competitivo, o Planejamento e Controle eficiente e eficaz podem revelar-se uma poderosa vantagem competitiva, permitindo às empresas ocupar uma posição de destaque em suas respectivas indústrias.

Conforme já foi mencionado, este estudo apresentou algumas limitações, principalmente decorrentes da dificuldade na obtenção de dados primários, o que sobremaneira limita uma maior abrangência da pesquisa, bem como impossibilita a realização de inferências estatísticas. Contudo, a existência de tais limitações de forma alguma invalida os resultados aqui demonstrados, já que foram obtidos mediante a aplicação de metodologias de caráter científico.

Até como fruto das limitações encontradas, as recomendações para estudos futuros repousam sobre uma maior abrangência amostral, o que irá implicar na obtenção de dados primários vindos de demais fontes. Também se pode sugerir que o método quantitativo seja posteriormente acompanhado de uma avaliação qualitativa das respostas, por meio do emprego de entrevistas em caráter amostral. Estas entrevistas serviriam para identificar e eliminar eventuais interpretações equivocadas em relação ao conteúdo da pesquisa, evitando-se desta forma algum viés na interpretação dos dados.

\footnotetext{
Abstract

To plan and to control are inherent functions to the administrative process, and there are some basic procedures that guide these activities. The group of these procedures composes the traditional model of planning and control. However, it is growing the questioning in the circle academic and business, on the effectiveness of the traditional model of planning and control. At the same time are appearing alternative methodologies for execution of such functions, that suggest a critical analysis of the traditional procedures, questioning the validity of the same with regard to the creation of value. This study, conducted with a sample of Brazilian companies publicly-traded in Bovespa, it aimed to show a statistical relationship between the existence of systematic program of planning
} 
and control (budgeting), and the obtaining of a result operational financial superior. Parallel also it was researched the adherence of new methodologies as well as the degree of satisfaction of the companies in relation to their procedures for planning and control.

key-words: planning and control, budget, value.

\section{Referências}

AAKER, David A. Administração estratégica de mercado. 5 ed. Porto Alegre: Artmed, 2001.

BANHAM, R. Better Budgets. Journal of Management Accounting, Febr. 2000.

BRIMSON, James; ANTOS, John. Driving Value Using Activity-Based Budgeting. United States of America: Jonh Wiley \& Sons, Inc., 1999.

CATELli, Armando. Controladoria - Uma Abordagem da Gestão Econômica GECON. 2. ed. São Paulo: Atlas, 2001.

CHIAVENATO, Idalberto. Introdução à Teoria Geral da Administração. São Paulo: McGraw-Hilll, 1983

FARRAGHER, Edward J.; KLEIMAN, Robert T.; SAHU, Anandi P. The Association Between the Use of Sophisticated Capital Budgeting Practices and Corporate Performance. The Engineering Economist, v. 46, n. 4, p. 300-311, 2001.

cross'ref

FISHER, L. Cover Feature: Budgeting - One Step Beyond. Accountancy, London, v. 129, n. 1303, Mar. 2002.

FREZATTI, Fábio. Orçamento Empresarial. São Paulo: Atlas, 2000.

HOPE, Jeremy; FRASER, Robin. Beyond Budgeting - How Managers Can Break Free from the Annual Performance Trap. Boston: Harvard Business School Publishing Corporation, 2003.

HOWELL, Robert A. Turn Your Budgeting Process Upside Down. Harvard Business Review, Boston, v. 82, p. 21-22, July / August, 2004.

JENSEN, M. Paying People to Lie: The Truth About the Budgeting Process. Harvard Business Review, Boston, Working Paper 01-07, Sep. 2001.

KAPLAN, Robert; NORTON, David. The Strategy-Focused Organization - How Balanced Scorecard Companies Thrive in The New Business Environment. Boston: Harvard Business School Publishing Corporation, 2001.

LEAHY, T. As 10 maiores armadilhas do orçamento. HSM Management, São Paulo, n. 32, p. 138-142, Maio-Junho 2002.

LIBBY, T.; LINDSAY, R.M. Budgeting - An Unnecessary Evil. CMA Management, Hamilton, v. 77, n. 1, p. 30-33, Mar. 2003.

MONTGOMERY, Cynthia A.; PORTER, Michael E. Estratégia: A Busca da Vantagem Competitiva. 7. ed. Rio de Janeiro: Campus, 1998.

NEUMANN, B. Streamline budgeting in the new millennium. Strategic Finance, Montvale, v. 83, n. 6, p. 44-49, Dec. 2001.

PORTER, Michael E. Vantagem Competitiva. Rio de Janeiro: Campus, 1989.

RAPPAPORT, Alfred. Gerando valor para o acionista: um guia para administradores e investidores. São Paulo: Atlas, 2001.

SANVICENTE, Antonio Zoratto; SANTOS, Celso da Costa. Orçamento na Administração de Empresas: Planejamento e Controle. São Paulo: Atlas, 2000. 
SMITH, D. Better than Plan: Managing Beyond the Budget. Leader to Leader, New Jersey, n. 15, p. 33-39, Winter 2000 .

TUNG, Nguyen H. Orçamento Empresarial e Custo Padrão. 4. ed. São Paulo: Edições Universidade Empresa, 1994. WELSCH, Glenn A. Orçamento Empresarial. 4. ed. São Paulo: Atlas, 1983.

WELSCH, Glenn A.; HILTON, Ronald; GORDON, Paul. Budgeting: Profit Planning and Control. New Jersey: Prentice-Hall, 1988.

\section{Dados dos autores:}

\section{Lucio Pandolfi Jr.}

Mestre em Administração de Empresas pela Universidade Presbiteriana Mackenzie.

Higienópolis, São Paulo/SP, Brasil, CEP. 01302-907

Tel. (11) 5549-4564.

e-mail: luciopandolfi@yahoo.com.br

\section{Wilson Toshiro Nakamura}

Doutor em Administração pela Faculdade de Economia, Administração e Contabilidade da Universidade de São Paulo - FEA/USP.

Professor do Programa de Pós-Graduação em Administração de Empresas - Stricto Sensu da Universidade Presbiteriana Mackenzie.

Higienópolis, São Paulo/SP, Brasil, CEP. 01302-907

Tel. (11) 2275-1970.

e-mail:wtnakamura@uol.com.br

\section{Diógenes Manoel Leiva Martin}

Doutor em Administração de Empresas pela Escola de Administração de Empresas de São Paulo EAESP/FGV.

Professor do Programa de Pós-Graduação em Administração de Empresas - Stricto Sensu da Universidade Presbiteriana Mackenzie.

Higienópolis, São Paulo/SP, Brasil, CEP. 01302-907

Tel. (11) 3865-5153.

e-mail: diomartin@mackenzie.br

\section{Douglas Dias Bastos}

Mestre em Administração de Empresas pela Universidade Presbiteriana Mackenzie.

Professor da Universidade Presbiteriana Mackenzie e da Faculdade Santa Marcelina.

Higienópolis, São Paulo/SP, Brasil, CEP. 01302-907

Tel: (11) 2692-2432.

e-mail: dobastos@uol.com.br 